F O R UM

\title{
Tuchtrechtbrief Minister van VWS: oplossing van welk probleem?
}

\author{
Prof.mr.W.R. Kastelein ${ }^{I}$
}

1

I N L E I D I N G

Op I7 november 2008 heeft de Minister van Volksgezondheid, Welzijn en Sport zijn zogenaamde tuchtrechtbrief naar de Tweede Kamer gestuurd. Daarin heeft hij zijn voornemens vastgelegd inzake de modernisering van het wettelijk tuchtrecht in de gezondheidszorg zoals geregeld in de Wet op de beroepen in de individuele gezondheidszorg (Wet BIG). Deze brief is een vervolg op het rapport van de zogenoemde commissie-Huls over het wettelijk geregeld tuchtrecht. ${ }^{2}$ De minister stelt in zijn brief dat er een zeer brede maatschappelijke behoefte is aan een wettelijk geregeld tuchtrecht in de gezondheidszorg ter bewaking en bevordering van de kwaliteit van de beroepsuitoefening. Dat ziet hij dan ook als het primaire doel van het tuchtrecht en niet de individuele genoegdoening van de klager. Dit uitgangspunt is conform de huidige doelstelling van het tuchtrecht in de individuele gezondheidszorg.

Ondanks het hierboven geformuleerde uitgangspunt lijkt de brief van de minister toch op twee gedachten te hinken. Enerzijds zijn er voorstellen om de positie van de klager te versterken en die niet de kwaliteit van de beroepsuitoefening maar de individuele genoegdoening van de klager betreffen, bijvoorbeeld het instellen van een zogenaamd vol beroepsrecht. Anderzijds wordt een kwaliteitsbevorderende maatregel van het tuchtrecht zoals een grotere medische inbreng in de colleges afgewezen, evenals het uitbreiden van (de interpretatie van) de tweede tuchtnorm tot het handelen van managers in de gezondheidszorg. Dit laatste is bijvoorbeeld niet overeenkomstig het rapport van de commissie-Huls. ${ }^{3}$

De brief van de minister wekt de indruk dat er wel goede voornemens zijn, maar dat er een onvoldoende analyse is gemaakt van de problemen die het tuchtrecht op dit moment in zich bergt. Dit is verbazingwekkend omdat er een uitvoerig evaluatierapport is over de Wet BIG, ${ }^{4}$ inclusief voorstellen tot verbetering voor het daarin geregelde tuchtrecht, en daarnaast een keur aan publicaties over het tuchtrecht in de gezondheidszorg waarin voorstellen tot verbetering worden gedaan. ${ }^{5}$ Verder besteedt de brief veel aandacht aan relatief kleine problemen zoals het verbeteren van de proce-

I. Willemien Kastelein is bijzonder hoogleraar Gezondheidsrecht aan de Radboud Universiteit te Nijmegen en tevens advocaat/partner bij KBS Advocaten te Utrecht.

2. Werkgroep tuchtrecht, Beleidsuitgangspunten wettelijk geregeld tuchtrecht, ook wel rapport Huls genoemd, Den Haag: Ministerie van Justitie 2006.

3. Rapport Huls 2006, p. 40 (zie noot 2).

4. ZonMw, Evaluatie Wet op de beroepen in de individuele gezondheidszorg, reeks evaluatie regelgeving: deel I2,

Den Haag: ZonMw 2 oktober 2002.
5. W.R. Kastelein, 'Tuchtrecht in de Wet BIG, ervaringen in 1997-200o', TvGR 2000, p. 425-434; P.H. Kahn, 'Tuchtrecht is aan revisie toe, gelijke beroepsrechten van klager en beklaagde', Medisch Contact 2007, p. I049-I05I; J.K.M. Gevers, 'De modernisering van het tuchtrecht: kanttekeningen bij het rapport Huls', TvGR 2007, p. 5I6-523; R.W.M. Giard, 'Medisch tuchtrecht: duidelijke bestaansredenen, onzeker nut', $N T v G$ 2007, p. 28-32. 
dure van de tuchtrechtspraak en is er weinig aandacht voor relatief grote problemen zoals bijvoorbeeld de positie en rol van de Inspectie voor de Gezondheidszorg (IGZ) alsmede het geringe gebruik van de spoedprocedure.

In dit forum behandel ik vier problemen die zowel in de tuchtrechtbrief als in het rapport van de commissie-Huls aan de orde komen voor zover het het 'medisch' tuchtrecht betreft. Het eerste probleem is dat er veel ongegronde en niet-ontvankelijke klachten worden ingediend waardoor het vertrouwen in het tuchtrecht onder druk staat. Het tweede probleem is dat er te weinig gebruik wordt gemaakt van de spoedprocedure door de IGZ en dat de IGZ überhaupt veel afwezig is in tuchtprocedures. Het derde probleem is het punt van de ketenzorg en het vierde probleem dat van de transparantie van de uitspraken van tuchtcolleges.

Bij de tuchtcolleges voor de gezondheidszorg wordt een groot deel van de ingediende klachten als ongegrond afgewezen. ${ }^{6}$ Ook wordt een aanzienlijk aantal klachten nietontvankelijk verklaard. Een van de redenen waarom veel klachten als ongegrond worden afgewezen is dat patiënten onvoldoende adequaat kunnen beoordelen welke klachten bij het tuchtcollege thuis horen en welke niet. Gezien de doelstelling van het tuchtrecht zou het streven moeten zijn dat alleen klachten die direct de kwaliteit van de beroepsuitoefening betreffen aan de tuchtcolleges ter beoordeling worden voorgelegd. De minister wil dit probleem oplossen door een goede voorlichting c.q. bewegwijzering, er op neerkomend dat klager in het klaagschrift verplicht is te vermelden of en zo ja welke stappen hij voorafgaand aan de schriftelijke klacht heeft gezet en wat daarvan het resultaat is. Bespreking van de klacht met de beroepsbeoefenaar zal geen voorwaarde worden voor ontvankelijkheid bij de tuchtrechter. Wel krijgt de tuchtrechter de bevoegdheid om de klacht naar de toepasselijke klachteninstanties door te zenden.

Niet duidelijk is of deze verwijzingsbevoegdheid van de tuchtrechter betekent dat een ingediende klacht dan ook niet-ontvankelijk kan worden verklaard omdat een klager met zijn klacht niet (eerst) de toepasselijke klachtenprocedure heeft doorlopen. Eveneens is onduidelijk of het tuchtcollege na doorverwijzing van het in behandeling nemen van de klacht kan afzien of dat, als de doorverwijzingsprocedure doorlopen is, de klacht altijd in behandeling moet worden genomen. Als de twee eerstgenoemde consequenties inderdaad door de minister bedoeld zijn, zal dit zeker een aantal ongegronde klachten schelen. Anderszins werpt dit weer een hogere drempel op voor klagers, hetgeen de minister nu juist wil vermijden. Het zal de efficiency van de tuchtrechtprocedure echter zeker ten goede komen.

Uit de tuchtrechtbrief is niet duidelijk of de minister kennis heeft genomen van het preadvies van De Die dat zij in 2008 voor de Vereniging van Gezondheidsrecht uit-

6. Het percentage bedraagt meer dan $80 \%$. Door een andere telling lijkt het alsof tegenwoordig minder klachten als ongegrond worden afgewezen maar dat is hem gelegen in de wijze waarop de tuchtcolleges tegenwoordig cijfers in het jaarverslag presenteren (zie <www.tuchtcollege-gezondheidszorg.nl>, Jaarverslag tuchtcolleges 2007 en 2008). 
bracht. Z Zij stelt voor om een zestal soorten klachten niet-ontvankelijk te laten verklaren, althans door het tuchtcollege niet in behandeling te laten nemen, variërend van communicatiestoornissen die niet tot ernstige gevolgen voor de patiënt hebben geleid tot klachten die niet zijn voorgelegd aan een klachtenfunctionaris of een klachtencommissie. Ook tekortkomingen van geringe ernst of waarbij inmiddels maatregelen zijn genomen ter voorkoming ervan respectievelijk ter verbetering van de zorg, dienen haars inziens niet door het tuchtcollege in behandeling te worden genomen.

Haar voorstellen zouden tot een aanmerkelijke daling van het aantal in behandeling te nemen tuchtklachten leiden. Dit zou ook de kwaliteit van de tuchtrechtspraak ten goede komen en tevens het vertrouwen dat patiënten in die tuchtrechtspraak hebben. Hoewel de voorstellen van De Die ongetwijfeld tot discussies kunnen leiden over de grenzen van de ontvankelijkheid, steun ik ze wel. Anders dan in een civiele of bestuursrechtelijke procedure is er voor klagers nauwelijks of geen drempel om een klacht bij het tuchtcollege in te dienen. Dat zij dan vervolgens teleurgesteld zijn over het aantal niet tot genoegdoening leidende klachten, is voorspelbaar. Bovendien wordt het tuchtcollege daardoor nodeloos belast met zaken die niet van belang zijn voor de kwaliteit van de beroepsbeoefening terwijl dat nu juist wel het primaire doel van het tuchtrecht is.

Dit brengt mij tevens tot steun voor het andere voorstel van De Die, namelijk om de tweede tuchtnorm ruimer te interpreteren. In de tuchtrechtbrief wordt hier nu juist niet voor gepleit in die zin dat beroepsbeoefenaren in hun hoedanigheid van managers, zoals een voorzitter van de raad van bestuur, niet onder het bereik van de tweede tuchtnorm vallen. Deze beperking miskent naar mijn mening de primaire rol van het tuchtrecht, namelijk bewaking van de kwaliteit van de beroepsuitoefening. Als een lid van de raad van bestuur in zijn beroepsuitoefening steken laat vallen, waardoor bijvoorbeeld de kwaliteit van een intensive care onder de maat is, dan dient hij daarop wel degelijk tuchtrechtelijk te kunnen worden aangesproken. De tweede tuchtnorm laat daarvoor ruimte genoeg. Waarom dit falen buiten het bereik van het tuchtrecht dient te worden gehouden, is niet duidelijk. Vanzelfsprekend zijn er leden van de raad van bestuur die niet-BIG-geregistreerd zijn maar dat geldt voor andere beroepsbeoefenaren evenzeer. Het feit dat bijvoorbeeld een helpende of verzorgende niet-BIGgeregistreerd is, is geen reden om een verpleegkundige die hetzelfde soort werk doet niet onder het tuchtrecht te laten vallen. De kern van het tuchtrecht is immers dat het zich alleen uitstrekt over BIG-geregistreerden. De instelling kan door de IGZ natuurlijk worden aangesproken op grond van haar toezichthoudende taak krachtens de Kwaliteitswet zorginstellingen, maar dat doet mijns inziens aan de tuchtrechtelijke verantwoordelijkheid van het BIG-geregistreerde lid van de raad van bestuur niet af. De maatregelen die de IGZ op grond van de Kwaliteitswet kan opleggen, namelijk het bevel en de aanwijzing, richten zich bovendien tegen de instelling en niet tegen de bestuurder persoonlijk zoals in het tuchtrecht. ${ }^{8}$

7. A.C. de Die, 'Gewaarborgde kwaliteit', in:J.H.H.M Dorscheidt \& A.C. de Die, De toekomst van de Wet BIG, preadvies 2008 Vereniging voor Gezondheidsrecht, Den Haag: Sdu Uitgevers 2008.
8. Aan de individuele beroepsbeoefenaar, niet werkzaam in een instelling vallend onder de reikwijdte van de Kwaliteitswet, kan de IGZ op grond van de Wet BIG overigens eveneens een bevel opleggen. 
Beperking van de toegang tot de tuchtrechter en een ruimere interpretatie van de tweede tuchtnorm zal mijns inziens het vertrouwen in en de efficiency van het tuchtrecht kunnen vergroten.

Recentelijk is er rumoer ontstaan over disfunctionerende beroepsbeoefenaren en het feit dat de IGZ met hen niet-openbare, beroepsbeperkende afspraken had gemaakt. ${ }^{9}$ Juist bij dit soort voorbeelden, zoals de neuroloog in Twente, blijkt de kwaliteit van de beroepsuitoefening ernstig in het geding. Dergelijke voorbeelden pleiten er mijns inziens voor om de IGZ een grotere, maar ook een tot meer activiteit verplichtende, rol in het tuchtrecht te geven: als klager en als helpende instantie voor patiënten of nabestaanden die een klacht willen indienen, maar die het vaak aan deskundigheid ontbreekt en die niet over de financiële middelen beschikken om rechtsbijstand in te schakelen. Daarbij zou ook de onbevredigende situatie tot het verleden behoren dat klagers een klacht indienen bij de IGZ en een kort briefje krijgen dat zij zich kunnen/ moeten wenden tot een klachtencommissie of het tuchtcollege.

Het mogelijke tegenargument van de IGZ dat een tuchtprocedure soms lang duurt en veel inzet van menskracht vraagt, is niet-valide. In de eerste plaats niet omdat het in het geheel niet nodig is dat een tuchtprocedure lang duurt. Er is immers een spoedprocedure. Daarvan wordt echter nauwelijks gebruik gemaakt. In de tweede plaats niet omdat een tuchtprocedure weliswaar complex kan zijn, maar een procedure op tegenspraak is dat als gevolg van de noodzakelijke fair play tot op zekere hoogte altijd. De uit te spreken maatregelen zijn wel bij uitstek geschikt om de kwaliteit van de beroepsuitoefening in stand te houden. Bovendien volgt de IGZ in dat geval de 'koninklijke' en transparante weg door aan een rechterlijk college het handelen van de beroepsbeoefenaar ter openbare toetsing voor te leggen.

Daarnaast zou de IGZ naar mijn mening ook een pregnante rol moeten vervullen in het toezicht op de door tuchtcolleges opgelegde voorwaardelijke maatregelen.

De IGZ zou door al deze maatregelen een veel sterkere rol in het tuchtrecht krijgen, hetgeen een goede zaak is, omdat juist de IGZ er bij uitstek is om de kwaliteit van de beroepsuitoefening te bewaken en te bevorderen. Een adequaat gebruik van de spoedprocedure en het vaker inzetten van de IGZ als klager zal niet alleen het vertrouwen in het tuchtrecht maar ook het vertrouwen in de IGZ ten goede komen.

Dit brengt mij ook op een ander voorstel van De Die over de rol van de IGZ die mede verband houdt met de ketenzorg en waarbij zij voorstelt om de inspecteur een vooronderzoek te laten doen om te bezien welke beroepsbeoefenaren bij een klacht betrokken zijn en vervolgens een eventueel aanvullende klacht in te dienen. Dit voorstel lijkt mij beter dan het voorstel dat de minister in de tuchtrechtbrief doet en dat er op neerkomt dat tuchtcolleges in het vooronderzoek daarnaar onderzoek zouden

9. IGZ, Onderzoeksverslag inspectiehandelen bij gebeurtenissen rond een neuroloog in Twente, rapport i7 februari 2009, zie <www.minvws.nl>; Brief Minister VWS van
I9 februari 2009, Kamerstukken II 2008/09, 31 700 XVI, nr. I30. 
moeten gaan doen en de klachten tot aan de zitting ambtshalve dan wel via klagers zouden kunnen uitbreiden. Echter, tuchtcolleges moeten zich beperken tot BIGgeregistreerde beroepsbeoefenaren en de IGZ heeft op grond van de Wet BIG en de Kwaliteitswet een veel ruimere mogelijkheid tot het treffen van maatregelen, zo nodig voor niet-BIG-geregistreerde beroepsbeoefenaren buiten het tuchtrecht om. Dit zal vanzelfsprekend alle problemen rond de ketenzorg niet tackelen, maar wel de mogelijkheden daartoe vergroten. Qua financiële consequenties maakt het niet uit of het tuchtcollege of de IGZ dit zal gaan doen. Voor beide organen geldt dat voor een dergelijke taak extra middelen ter beschikking zullen moeten worden gesteld. ${ }^{\text {Io }}$ Daarnaast zal mijns inziens in overweging kunnen worden genomen om ook klagen tegen een maatschap/personenvennootschap of vakgroep van BIG-geregistreerde beroepsbeoefenaren open te stellen. Zij dragen immers een gezamenlijke verantwoordelijkheid voor de kwaliteit van zorg van hun (vak)groep. Daarmede zou bijvoorbeeld ook voorkomen kunnen worden dat een klacht over het handelen van een arts(-assistent) wordt afgewezen omdat over de verkeerde arts wordt geklaagd. Terecht neemt de minister het voorstel tot het instellen van een klachtrecht tegen rechtspersonen niet over. Dit zou geen recht doen aan het individuele karakter van het tuchtrecht in de

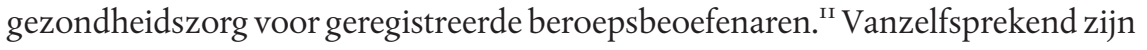
alle problemen rond ketenzorg hier niet mee opgelost, maar dat kan ook niet via het tuchtrecht al was het maar omdat het tuchtrecht zich alleen uitstrekt en blijft uitstrekken tot BIG-geregistreerde beroepsbeoefenaren.

Ten slotte het punt van de transparantie van de uitspraken. De minister lijkt zich niet te realiseren dat reeds alle tuchtrechtelijke uitspraken op internet worden gepubliceerd zodat de uitspraken voor een ieder te raadplegen zijn. Dit wil vanzelfsprekend niet zeggen dat deze uitspraken ook allemaal tot het beoogde doel van kwaliteitsbevordering leiden. In feite is daar het patiëntenperspectief, hoe onbevredigend wellicht ook voor de individuele patiënt, onbelangrijk en gaat het met name om het perspectief van beroepsbeoefenaren. (Bewerkte) publicatie in medische- en andere tijdschriften die zich op beroepsbeoefenaren richten is daarvoor mijns inziens het beste middel. Dat betekent echter wel dat deze uitspraken ook geanalyseerd dienen te worden door medische- en/of juridische deskundige(n). De huidige wijze van publicatie voldoet daaraan niet. Mochten de tijdschriften van/voor beroepsbeoefenaren hiervoor onvoldoende gelegenheid, ruimte of deskundigheid hebben dan verdient het wellicht aanbeveling dat het ministerie of de IGZ een tijdschrift opricht waarbij zij uitspraken samenvatten, laten analyseren en van commentaar voorzien. ${ }^{\text {I2 }}$

Io. Overigens is het voorstel om dit de IGZ te laten doen bijvoorbeeld veel gelijkend op de rol van de deken in de Advocatenwet.

II. Zie ook rapport Huls, p. 4I (zie noot 2).

I2. Voor een aantal specialismen, zoals de tandarts, de chirurg, de gynaecoloog, de anesthesist, de huisarts en de apotheker is een analyse van de ongepubliceerde tuchtrechtelijke jurisprudentie in boekvorm verschenen maar dat beperkt zich dan tot één specialisme, zie bijvoorbeeld M.B. van Leusden, H.A.M. Vervest \& J.H. Hubben, Gynaecoloog en tuchtrecht 1992-2004, Den Haag: Sdu Uitgevers 2005. 
Bovenstaande voorstellen zullen mijns inziens de problemen van het geringe vertrouwen in het tuchtrecht kunnen doen herstellen. Het zal leiden tot veel minder ongegronde klachten en tot een grotere transparantie van en begrip voor tuchtrechtelijke uitspraken. Daarmede zijn vanzelfsprekend niet alle problemen opgelost, maar dat kan ook niet. Nog twee kleinere discussiepunten wil ik noemen. Punt van beraad zou kunnen zijn het toekennen van schadevergoeding. De minister stelt dat dit niet in het tuchtrecht thuishoort, hoewel tuchtzaken daarvoor als voorbereiding soms natuurlijk wel gebruikt worden. In ieder geval vergt het toekennen van schadevergoeding een juridische kwalificatie, onder meer ten aanzien van het causaal verband waarvoor de samenstelling van de tuchtcolleges minder geschikt zou kunnen zijn. ${ }^{13}$ De vraag is of dat een valide argument is. In andere rechtssoorten is de enkelvoudige kamer voor eenvoudige zaken immers al lang geaccepteerd. Voor eenvoudige zaken zie ik daarin geen grote problemen bij schades tot bijvoorbeeld $€$ 5.ooo of $€$ Io.ooo. Die komen wellicht in strikt medische zaken niet veel voor, maar bijvoorbeeld in tandartsenzaken wel en schadevergoeding zou voor die patiënten een oplossing kunnen betekenen. Aangezien van het huidige instrument van de wettelijke boete weinig tot geen gebruik wordt gemaakt, is het te overwegen om dit instrument om te zetten in een (geringe) schadevergoedingsmogelijkheid aan patiënten.

Een aantal voorgestelde maatregelen van procedurele aard, zoals geen verplicht vooronderzoek als er een zitting wordt gepland en geen verplichting tot zitting in hoger beroep, lijken mij zeker de kwaliteit van tuchtrechtspraak ten goede te kunnen komen, evenals de mogelijkheid een klacht als ongegrond af te wijzen zonder een maatregel op te leggen.

In mijn analyse komt de klager er op het eerste gezicht wellicht bekaaid af, maar dat is conform het primaire doel van het tuchtrecht, omdat het tuchtrecht er niet voor hem is. Het is er immers voor de kwaliteit van de beroepsuitoefening. Daarin past overigens wel het openbaar maken van namen van zorgverleners die beroepsbeperkende maatregelen zijn opgelegd zoals de minister voorstelt en een veel betere raadpleegbaarheid van het BIG-register, zowel voor patiënten als voor tuchtcolleges. ${ }^{\text {I4 }}$

Al met al is de tuchtrechtbrief van de minister op onderdelen een stap op de goede weg maar dient een aantal punten zeker nog nader bekeken te worden, met name hoe de vele, kennelijk ongegronde klachten kunnen worden teruggedrongen en de positie van de IGZ versterkt kan worden. De voorstellen van de minister daartoe acht ik onvoldoende.

I3. Zie voor bezwaren:J.K.M. Gevers, 'De modernisering van het tuchtrecht: kanttekeningen bij het rapport Huls', TvGR 2007, p. 5I6-523 en standpunt KNMG over toekomstige regeling van het wettelijk tuchtrecht 9 oktober 2009, zie < knmg.artsennet.nl>.
I4. Zie persbericht VWS 5 juni 2009: 'Zwarte lijst' voor medici op internet; zie voor - terechte - bezwaren:M.A.J.M. Buijsen, 'Zwarte lijsten in de gezondheidszorg - vergeet de waarborgen niet!', NJB 2009, p. II42 e.v. 